\title{
ANNALS
}

OF THE

\section{AMERICAN ACADEMY}

OF

POLITICAL AND SOCIAL SCIENCE.

THE GROWTH OF THE FRENCH CANADIAN

RACE IN AMERICA.

It would be idle to suggest that economists have come to anything like a general agreement regarding Malthus' "Laws of Population," and it is too late, nowadays, to rest content with expressing the somewhat contemptuous wish that critics might well employ a portion of their leisure in reading the essay which they criticise. The whole problem is still in controversy, and is likely to remain so wherever the industrial conditions under which Malthus wrote are absent. A great deal of the criticism amounts to little more than a disproportionate statement of some of the checks to population; a sort of criticism which is really a corroboration of the theory criticised. All the evidence collected and published since the essay appeared has gone to show that population rarely treads on the limits of subsistence, and that "by a natural tendency, without any violent repression from external forces or any painful restraint on desires, population has grown less rapidly than wealth." * This, however, is simply

*Levasseur's "La Population Francaise," Vol, iii, p. Iog.

[2 13 3] 
further evidence in addition to that which Malthus accumulated in the successive editions of the essay, whose many lacune and imperfections he readily admits. It bears out what he says about the operation of checks on the principle of population; and demonstrates that the moral check is much more important than the physical checks, and that for the "limits of subsistence" we must substitute the "standard of comfort." The theory of the "Iron Law of Wages" has undergone a similar modification, and in becoming more accurate has become less exact and precise. Speaking generally, one may say that his critics have endeavored to show that in numberless instances and from an infinite variety of social, political, economic and religious causes, the "Laws" were steadily counteracted, and produced no effect, and that therefore such laws could not exist. What they should have shown was that the laws were so steadily counteracted by forces which were as strong and as permanent as the alleged laws themselves, that it became a mere barren and formal statement to express them as Malthus had done; that while it might be true that the checks of vice and misery were simply the indirect methods by which the ultimate check of famine operates, this could not be claimed of the check on population exercised through moral restraint. In a note to the appendix (6th Ed., Vol. ii, p. 453), Malthus writes: "It has been said that $I$ have written a quarto volume to prove that population increases in a geometrical ratio, and food in an arithmetical ratio; but this is not quite true. The first of these propositions I considered as proved the moment the American increase was related, and the second proposition as soon as it was enumerated. The chief object of my work was to inquire what effects these laws, which I considered as established in the first six pages, had produced and were likely to produce on society-a subject not very readily exhausted. The principal fault of my details is that they are not sufficiently particular; but this was a fault which it 
was not in my power to remedy. It would be a most curious, and to every philosophical mind, a most interesting piece of information, to know the exact share of the full power of increase which each existing check prevents; but at present I see no mode of obtaining such information."

This is indeed " one ha'penny worth of bread to this intolerable deal of sack," and it seems rather disproportionate that the law should be established in six pages, while a "quarto volume" was required to explain why the theory and the facts did not correspond. The main object of the essay, as may be seen even by running through the table of contents, was to explain the counteracting causes - to explain, for instance, the fact that while, at the end of the second century, the population of the Roman Empire was about 45 millions, to-day the population of the same region does not exceed $15^{6}$ millions, giving an annual rate of increase of merely .0007 per cent. To say in such an instance as this that the natural tendency of population is to increase at the annual rate of 3.I9 per cent, doubling itself every twenty-five years, is to make a purely formal statement. The "counteracting" causes are so much the more effectual, that to call them counteracting causes seems a ludicrous disproportion. The utmost that can possibly be said is that of all the forces present, that stated in Malthus' law is relatively the strongest, and we cannot say what degree of strength it has till we have determined " the exact share of the full power of the increase which each existing check prevents." The line which critics should have taken was that the famous "Laws of Population" were purely hypothetical and mere devices of arrangement for classifying the known facts. The place of hypothesis in economics has been much discussed, with the generally accepted conclusion that an hypothesis is little more than a device of arrangement. An hypothesis may be a more or less adequate system for arranging and classifying; and judging from the disproportions of the essay, it might have been said that [2I5] 
Malthus had hit upon the wrong hypothesis, that some one of the forces which he discusses as checking the increase of population might have served as a better principle of classification than the one he chose.

Indeed, from such a point of view, it is really immaterial what hypothesis has been chosen, and the whole ardor of the controversy would have been out of place. There can be no doubt, however, that Malthus meant his principle of population to have immediate practical application. The sub-title of the essay (even in the sixth edition) indicates as much. It is " a view of its past and present effects on human happiness, with an inquiry into our prospects respecting the future removal or mitigation of the evils which it occasions." The very checks, the discussion of which occupies so much space, are nothing more than particular modes in which the ultimate check operates. Malthus, at least, puts forward the principle as an hypothesis which is an adequate expression of the facts.

From this point of view it becomes a matter of great importance that a standard should be established. If the phenomena are to be accurately estimated and measured, if the effects of the various counteracting checks are to be made definite, it is necessary that some standard rate of increase should be established, that it should not be arbitrary, but natural and capable of being applied in every community. It cannot be said that Malthus is anywhere at much pains to establish such a standard. He quotes from various sources, relying ultimately on the authority of Benjamin Franklin; and finally advances what he claims is a very moderate estimate, viz.: that population, when left to itself, will double every twenty-five years. He points out, by the way, that in many agricultural districts, where "vicious customs and unwholesome occupations are unknown," population has been found to double itself in much shorter periods; and he mentions that Sir William Petty, in his "Political Arithmetic," had given it as his

$$
\text { [216] }
$$


opinion that population might double itself within ten years. "But to be perfectly sure that we are far within the truth, we will take the slowest of these rates of increase, a rate in which all concurring testimonies agree, and which has been repeatedly ascertained to be from procreation alone.

" It may safely be pronounced, therefore, that population, when unchecked, goes on doubling itself every twenty-five years, or increases in a geometrical ratio." -Book I., c. i.

Considering how much depends on the standard rate of increase, one cannot say that Malthus has taken the task very seriously. Six pages can hardly be deemed a sufficient proportion of his space to be devoted to so important an end. It may be that his proposition that population increases in a geometrical ratio is proved so soon as " the American increase was related;"' but surely a little more consideration was necessary to show that this was the American rate of increase. The statistics on which he has based this moderate rate of increase are frequently drawn from local experiences, and are, as often as not, mere casual conjectures on which little reliance should have been placed. His own evidence goes to show that the rate of increase varied from being a minus quantity up to such a figure that population doubled itself in ten years; while in small new settlements the rate of increase was affected one way or another by local and temporary causes the nature of which we cannot now determine, and under conditions such that the compensatory effects of averages could not be experienced. Statistics of limited areas and short periods of time cannot be relied on to furnish a standard by which so much is to be judged. For it should be remembered that Malthus was incited to write his essay that he might forever silence the Utopians, such as Godwin and Condorcet, who dreamed of a new heaven and a new earth by a redistribution of wealth. But, even if we admit the substantial accuracy of his authorities, can we accept as a standard the experience of the New England States in the century and a half before 1800 ? Especially in its earlier half, 
this was a period of vicissitudes, as he himself admits by taking a cautious estimate. The growth of population must have been much affected by immigration which is relatively more important the farther back we go. Again, a tradition of having large families and the pressing necessity of a supply of agricultural labor which could be procured in no other way must have tended to promote a rapid growth of population. The evidence is too local and too temporary to support the conclusions based on it. The experience of the New England States is used to judge the whole course of history. The rate of increase there observed is set up as the normal rate in comparison with which all other rates of increase are abnormal, and to be accounted for by counteracting causes. Moreover one assumption, which is indeed explicitiy stated but in proof of which not even six pages, nor indeed six sentences, are devoted, runs through the whole essay; which is, that the natural "prolifickness" of all races is approximately equal, and that to establish the rate of increase for one race under the most favorable conditions is to establish the standard for all races. How much justification there may be for this last assumption need not here be discussed, but it is important that we should keep in mind that some such assumption is behind every application of the principle of population in a country other than that in which the standard rate has been observed and in industrial and social circumstances different from those under which the "standard" population lived.

Leaving the last assumption as Malthus stated it (and it is probably doubtful whether more than a general presumption in its favor could be established even by the most widereaching statistical research) we should first see under what conditions a standard could be found. It is obvious that a standard by which so much is to be judged should not be established except on the clearest evidence and under conditions which leave no room for doubt as to the forces at work in producing the observed result. 
The race whose rate of increase is to be taken as standard should also live under conditions which make it an easy matter to ascertain the true rate of increase. These, probably, would best be found in an isolated community, with little or no communication with the outer world or with its immediate neighbors, inhabiting a new country where the conditions of life are favorable for healthy and vigorous existence, and in which neither the nature of the soil or climate, nor the nature of the occupations of the inhabitants renders disease especially frequent. Above all, the race, by customs and traditions, and in every other possible way, should be little apt to assimilate surrounding or immigrating peoples or to amalgamate and lose its identity in that of the peoples among whom its lot may be cast. In short, the circumstances of the community must be such that we can clearly trace its growth and be reasonably certain that no branch of the race has escaped observation, and that the increase of no other race or community has gone to augment the results. In other words the circumstances must be such that we can discover the truth, the whole truth, and nothing that is not true.

It is not an easy matter to find a nation or race which fully realizes all these conditions. The movements of population during the present century render it almost impossible to discover the true rate of increase. European countries have lost, actually and potentially, by emigration. America and new countries have gained so much by immigration, potentially as well as actually, that no accurate deduction can be made from the rates of increase there observed. Before the present century the populations of Europe were less mobile than they have since become, but accurate statistics are not available. Wherever we turn the attainment of anything like accuracy seems impossible, and any standard of increase set up would retain the appearance of being arbitrary. Fortunately, however, there is one race which presents all the conditions necessary for accurate observation. The French population of Canada is an isolated, homogeneous 
body of which we cav observe the true increase; the whole increase, and nothing but the true increase, and from this source it is possible to set up a standard which shall not be arbitrary even in appearance.

To begin with, we are in possession of accurate statistical data covering two centuries and a half. Not only have regular enumerations of the people been taken since the country passed into the possession of England, there were sixteen enumerations before that event. Over and above these census returns, which might partake of the inaccuracy of all early census returns, we have at our disposal accurate vital statistics covering the whole period during which there have been French settlers on this continent. The parish registers kept by the priests, during nearly three centuries, give us a complete survey of the progress of the population. These registers were rendered accessible by publication in one of the volumes of the First Census of the Dominion of Canada in I $_{7} 7$ and the results may be, and have been, used not merely to verify but also to supplement the statistics gathered by the government agents. The registers contain an impartial account of births and marriages and deaths which are open to no suspicion of political interference. Thus, for the growth of the population, we have not the random guesses, more or less well informed, made by observers, more or less competent and more or less prejudiced, but a series of tables on whose accuracy we can depend; for their compilation was part of a religious function and not the work of a possibly perfunctory government department. In the case of the French Canadian population the first and most essential condition is realized. The rate of increase which may be established is based on reliable statistics and not on mere estimates; and these statistics cover a long period, long enough at any rate to eliminate accidental variations of time.

A second point of almost equal importance for establishing a standard rate of increase is that during nearly a century [220] 
and a half, ever since 1759, when New France passed on the Plains of Abraham into the possession of the English, the French Canadian has lived in isolation; and the consequence is, that whatever rate of increase we discover, will be a legitimate rate, not raised by immigration from abroad nor interfered with in other ways which might render the real increase uncertain. When the French Canadian became a subject of the British crown, he retained only a sentimental connection with the mother France across the seas. His language, his laws, his customs, and his religion were guaranteed to him forever, and a great deal of that vexatious regulation and interference which had hindered the development of the colony (and was indeed the reason why France failed as a colonial power) was removed. The French Canadian remained free to develop, and we shall take the first census after 1759 as the starting point of our calculation. Immigration from France which, prior to 1760 , must prevent the true and legitimate rate of increase from being readily discernible, ceased, and during a century and a half has remained practically a negligable quantity. It is true that there was a large emigration from Acadia to New France in consequence of English oppression; but it is very probable that the greater part took place before 1765 (our starting point). The French population of Acadia in I 765 slightly exceeded Io,000, and in 177 I still amounted (by estimate) to 8462 . The decrease in these six years was probably due more to the enormous mortality among the population on the North Shore than to emigration. Of late years a strong effort has been made by some of the leaders of the French Canadians to strengthen the bonds of sentiment which still unite them to France; and Quebec provincial loans have been negotiated in Paris, at an extravagant rate, rather than in London. The object has of course been to divert to Canada some portion of the scant stream of emigrants from France, and thus to reinforce French Canadian influence in Canada. An especial effort was made [221] 
in the early seventies to attract the inhabitants of Alsace and Lorraine who had expatriated themselves rather than become German citizens; but so far as can be seen, statistically, neither this special effort nor any other has had any marked effect. The number of French immigrants is still insignificant, and not appreciably greater than the number of German and other continental immigrants into the Province of Quebec. The following table shows the number of French and German born inhabitants of the provinces of Quebec and Ontario since $\mathrm{I} 85 \mathrm{I}$ :

Proportion per rooo owning as Birth Place.

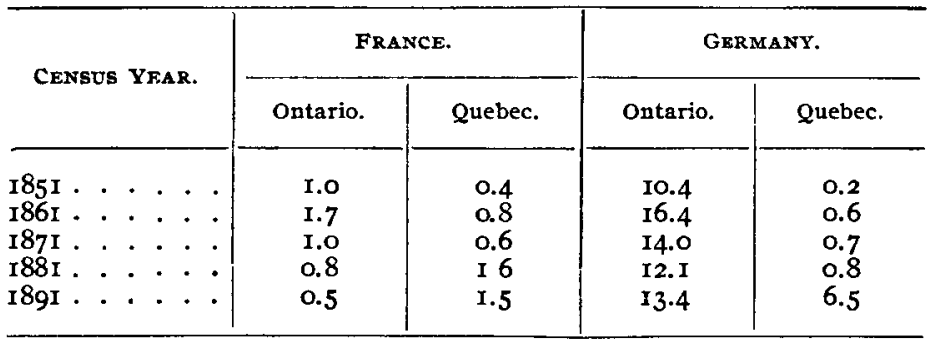

It is evident from this table that the rate of increase in French Canada has been augmented but little by immigration from France, and this is the only source from which error might come. The total immigration is in itself small, and there is no danger of confounding, at least from $185 \mathrm{I}$, any other part of it with the natural increase of the French Canadian people. The proportion of immigrants from France is certainly not more than sufficient to counterbalance the inevitable leakage which cannot be traced. Every nation loses more or less by emigration in driblets so small that no statistical account of it can be made. This leakage is less perhaps in the case of the French Canadians than in any other nation, but the increment of population by immigration from France is no more than sufficient to make up for the loss. 
The second condition of a reliable standard is therefore present. Malthus took the increase of the New England States as his standard and his standard is unreliable because of the steady stream of immigration which was even then flowing in, the increase due to immigration being then relatively the more important that the population was small. It happens that the standard he set up is accurate or approximately accurate, but it only happens so. In the case of the French Canadians we may take the increase from 1765, which we take as our starting point, to I890-9I, from 69,8 Io to $\mathrm{I}, 804,795$, as a natural increase.

While it is necessary that the natural rate of increase should not be augmented by immigration it is equally important that no part of the natural rate should be omitted on account of emigration. If the rate of increase in the United States, during last century and this, may not be taken as a standard on account of immigration, still less can the census reports of England during present century afford any basis for establishing a true standard. Even if we add to the thirtyeight millions of the present population of the United Kingdom, the thirteen or fourteen millions who have left the country since 1815 , we have not obtained a final result. We should still have to add the potential increase of these thirteen or fourteen millions. Even should we assume that these would have increased at the same rate as those who have remained, we have still only a conjectural rate of increase, based on the unverifiable, and probably false assumption, that the emigration of these millions made no essential difference in the rate of increase at home.

The people whose rate of increase may be accepted as a standard must not have lost to any great extent by emigration. We want the whole increase and not a part of it. At first sight it appears that the French Canadian people do not realize this third important condition. By means of the census reports issued by the Dominion Government, we can trace the decreasing movements of the French Canadian 
population within Canada. Whether they go to British Columbia or the Northwest, to Manitoba or to the Maritime Provinces, they are still within reach of the census enumerator and the total increase in Canada can be ascertained without much trouble. But there has been, over and above these movements within the Dominion, an enormous emigration into the United States, part of a general movement so great as to be called by the Canadians an Exodus. It is not enough for us to know that the French Canadian in the land of his adoption retains the language, the religion, the customs, the individuality of his race; it is not enough even to know, that in his new enviroment he remains an isolated, unassimilated unit, that he does not intermarry with the old in habitants or with other newcomers; that, in short, the increase is still a pure and natural increase, if, after all, we cannot estimate accurately in what numbers he has left his ancestral home. General estimates in round numbers are of little value for statistical purposes. Till recently we had to be content with general estimates. The census reports of the United States prior to I 890 made no distinction between English and French Canadians. We knew that there were so many hundreds of thousands of Canadians in the United States, but we did not know the proportions of the two nationalities. The instructions issued to the United States census enumerators in 1890 bade them distinguish between French and English Canadians and by the publication of two Census Bulletins, one, No. 357 (issued February 16, I893), dealing with "Foreign born population distributed according to country of birth I850-I890;" the other, Extra Census Bulletin No. 97 (issued November I, 1894), dealing with "Statistics of Foreign parentage," the information we require for the purposes of this essay has been made accessible. From these bulletins the lacunce in our statistics have been filled up and the necessary data supplied for estimating the rate of increase of the French Canadian people whether resident in Canada or in the United States. [224] 
We learn not merely how many French Canadians are resident in the United States but also the number of their increase of the first generation. The fact to which frequent and emphatic attention is called in these bulletins that the French Canadian does not intermarry either with the native born citizens of the United States or with foreign immigrants renders it possible to ascertain with exactitude the number of his increase. In comment on a table, p. 20, Extra Census Bulletin No. 97, Dr. Carroll D. Wright says, "It is at once apparent from these percentages that native born women have married most freely with those nationalities which were among the earliest contributors to our foreign born element, and for this reason it is impossible to determine accurately the proportion of these women who are themselves native born but of foreign extraction.

"The percentage of persons with French Canadian fathers and native mothers makes this assumption all the more plausible, for the reason that this class is not disposed to marry much, if at all, outside of its own people."

The figures referred to, as extracted from the table are:

Total white persons having French Canadian fathers, 497,650 .

Total having mothers born in French Canada, 442,04I; per cent, 88.83 .

Mothers born in other foreign countries, II,I44; per cent, 2.24 .

Mothers native, 44,465 ; per cent 8.93 .

Further on in the same bulletin, it is said: "An attempt has been made to determine for the first time the approximate number of persons in this country who were of French Canadian extraction (p. 21) ... "It appears that the whole number of the French Canadian element in this country in $1890 \ldots$ was 537,298 , while of the English Canadian (including Newfoundland) was $1,163,645$. There is an unavoidable duplication in this table of 6930 white persons having both parents born in Canada, one parent [225] 
being of English extraction, the other parent being of French extraction. This duplication is small, however, compared with the whole number of each element." (p. 24.)

We are thus able to trace with accuracy the growth of the population. We include none who have no right to be included, and what is equally important, we practically omit whom we should include. The only defect in the information derived from these bulletins is that no distinction is made between Canadian French and Acadian French. From the point of view of the United States statistician there is no reason why this distinction should be made, and, were it not that the early estimates of the Acadians are conjectural, there would be no reason for drawing the distinction in this examination. The estimates of the number of Acadians in 177 I remaining in what are now the Maritime Provinces, after the deportations, emigrations and returns had ceased, are calculated from the returns of the census of $187 \mathrm{I}$ on the supposition of a " natural increase at the rule of 2.5 per annum, the normal rate of the Acadians when left to themselves" (Census Report, 187I, Vol. IV, Introd., p. xxviii), which means that the Acadians double every thirty years. We shall see that this is rather less than the rate of increase among the French Canadians, but it would obviously be unsatisfactory to base any calculation of the rate of increase on an estimate based on an assumed rate of increase. "It was apparently only about I77 I that the Acadians saw the cessation of the emigration which had diminished their population, and that having again attained to easy circumstances, they began to increase at the rate of 2.5 per annum. It is at this rate, taking the census of 187 I for a basis, that the probable number of the Acadian population in each centre has been fixed.

in fact, the number of 8442 , in the ratio of increase indicated during the course of a century, accounts for the Acadian population of 99,740 souls (the Acadian population of Prince Edward Island and the State of Maine included) in 1871 . 
Exchanges of settlers from Acadia to Canada and vice versa, have taken place in the course of the century, but as these exchanges almost balance each other, they have not affected the general result"' (Ibid, p. xxxiv).*

Except for the petitio principii involved by including them, there would have been no reason for excluding them from our calculation. As the matter stands, however, it is better to make deduction from the total number of French Canadians returned in the census of $I 89 \mathrm{I}$ of the number of French Acadians in the Provinces of Nova Scotia, New Brunswick and Prince Edward Island. According to Table III, Vol. I, Canadian Census, I891, there were in

Nova Scotia, . . . . . . . . . 29,838 French

New Brunswick, . . . . . . . 61,767 "

Prince Edward Island, . . . . . . I I,847 “

Less number of Quebec French in

Maritime Provinces, . . . . . 3,500

Total Acadians, . . . I00,000

In I89 the census returns show a total of the French speaking population of Canada, $\mathrm{I}, 404,974$; so that after deduction of the number of Acadians, we find the total French Canadian population resident in Canada, I,304,974. The United States Bulletins, as mentioned above, do not make any distinction between French Canadian and French Acadian, but they afford the means of estimating approximately how many Acadians are included in the total of 537,298 French Canadians resident in the United States. We may safely assume that at least as large a proportion of Acadians as of French Canadians have joined the Exodus

\footnotetext{
* By calculation based on Table V, Census Report, I89I, it appears that there is a surplus of something like 3500 Canadian French resident in the Maritime Provinces (subtraction of Acadians in Quebec being made); and this number is accordingly included in the total of French Canadians resident in Canada.
} 
(popular estimate in New Brunswick is that the proportion is larger). The French Canadians in the United States are in rather more than the proportion of $I$ to 3 of the total French population of Canada; so that we are safe in assuming that more than 30 per cent of the Acadians are to be found in the United States-that is more than 30,000 . If, then, we reduce the number of French Canadians returned in the United States Census from 537,298 to 500,000 , we are probably within the mark.

The third condition for the establishing of the standard that no part of the natural increase should be omitted from the calculation is accordingly realized in the case of the French Canadians. The total increase of the people from 1765 to $1890-9 \mathrm{I}$ is ascertainable and the resulting rate is therefore not based on conjecture.

It is further important for the establishing of a standard rate of increase that the conditions of life and labor among the people whose increase is taken as standard, should be at least as favorable as in any other land; and there can be no doubt that this is true in the case of the French Canadian. The quelques arpents du neige as Voltaire contemptuously designated New France have during the century and a half been visited neither by war nor by pestilence (for we need not over-estimate the skirmishes of I8I2). There has been security of life and property, and freedom of development; there has been abundance of good land unappropriated; and, with inexhaustible fisheries and unexhausted forests, with developing industry at home and unrestricted freedom of migration, there never has been any danger of population treading on the limits of subsistence. The climate, though severe in winter, is, at heast, as favorable to healthy human existence as any other that could be named. So that taken all in all the general conditions are perfectly normal.

It may, however, be objected that all the conditions are not normal, and that the excessive birth-rate among the French Canadians prevents us from taking their rate of [228] 
increase as a standard. Malthus assumed, and as we said, probably without warrant, that there is a natural " prolifickness," which is the same for all nations, and that any divergence from this standard must be accounted for by means of the checks on population. But if it be true that the birthrate of the French Canadian is four or five times as high as the birth-rate of the English Canadian or of any other civilized race, then a good deal of the pains which Malthus takes to show how the operation of the checks accounts for the different rates of increase is labor thrown away. However valid the objection may be against Malthus' assumption, or perhaps more strictly against his manner of stating the assumption, it need not prevent us from using the French Canadian rate of increase as a standard.

There can be no doubt of the very general opinion in Canada and elsewhere that the French Canadians are increasing out of all proportion to the rest. Their excessive "prolifickness" is often the subject of remark, and the statement is met with profound scepticism that the size of the average family in Quebec is only a fraction larger than the average family in Ontario, or than the average family taking Canada as a whole, and is smaller by as large a fraction than the average family in Prince Edward Island. What about the tradition among the French Canadians, it is asked, that the twentieth or the twenty-fourth child in a family belongs to the parish priest, and is brought up and educated for the church? What about the law passed by the late Count Mercier in Quebec, providing that " every father or mother of a family, born or naturalized and domiciled in this Province, who has twelve children living, born in lawful wedlock, is entitled to one hundred acres of public lands selected by him" (C. 20, 53 Vict.) - an enactment which, but for the provision in favor of lawful wedlock, may be compared with a good deal of the legislation and practice connected with the relief of the poor at the end of last century in England? Yet in spite of prevalent opinion and of inferences naturally [229] 
enough drawn from such legislation, the facts are quite otherwise, as the following table must conclusively show:

Average Size of Family.

\begin{tabular}{|c|c|c|c|c|c|c|}
\hline Province. & & 1851. & I86I. & 1871. & I88I. & 189r. \\
\hline $\begin{array}{l}\text { Upper Canada, after I87 } \\
\text { Lower Canada, or Quebec } \\
\text { Nova Scotia } \\
\text { New Brunswick . } \\
\text { Prince Edward Island } \\
\text { Manitoba } \\
\text { Northwest Territories } \\
\text { British Columbia } \\
\text { All Canada . . . . . } \\
\text {. . }\end{array}$ & 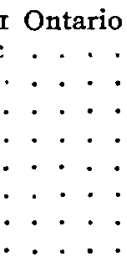 & $\begin{array}{l}6.2 \\
6.2 \\
6.1 \\
6.1 \\
.: \\
6 . \\
6.2\end{array}$ & $\begin{array}{l}6.4 \\
6.0 \\
6.0 \\
6.3 \\
. \quad . \\
.: \\
.0 . \\
6.2\end{array}$ & 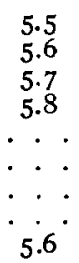 & $\begin{array}{l}5 \cdot 2 \\
5 \cdot 3 \\
5 \cdot 5 \\
5.6 \\
6.0 \\
4.6 \\
4.8 \\
4 \cdot 7 \\
5 \cdot 3\end{array}$ & $\begin{array}{l}5.1 \\
5.5 \\
5.4 \\
5.5 \\
5.8 \\
4.8 \\
4.6 \\
4.7 \\
5.2\end{array}$ \\
\hline
\end{tabular}

In one period alone has the average in Quebec been higher than the Canadian average, and then the Canadian average was low owing to the disturbance introduced by the statistics of the new western provinces, where the average is abnormally low. In $189 \mathrm{I}$, of all the Provinces the average rises in Quebec alone, but the rise is not sufficient to be more than a temporary interruption of a steady fall. The average in New Brunswick was equally large, and there only 25 per cent of the population are French; in Prince Edward Island, the average (5.8) is higher, and there only 18 per cent of the population are French; in Nova Scotia, the only other Province whose average exceeds the Dominion average, less than 7 per cent are French, while in Quebec four-fifths, or 80 per cent, of the population are French.

This result, which seems to confound all the popular notions regarding the extraordinary families common in French Canada, is really quite compatible with the received opinion. The number of children born into a family is so very much in excess of the number in other parts of Canada, and in other countries, that the assumption made by Malthus 
of a natural "prolifickness" which is approximately the same the world over, becomes quite untenable. Had Malthus maintained that in the absence of vice and misery there is a natural average of size of family, which is the same the world over, much more might have been said for the assumption. It does not appear that the extraordinary infant mortality (which is the explanation of the paradox) can be attributed to either vice or misery, the checks on which Malthus at first lays so much stress, and of course it cannot, in a Catholic country, be due to the prudential check as interpreted by the neo-Malthusian. The causes are various, but neither scarcity of food nor general misery can be included among them. The French Canadian is not a weakling, and the women are not such as give birth to sickly children. One prevalent cause, infantile diarrhcea, is due rather to excess of food, improper food, and lack of care about the child's diet, than to poverty and want. The following table is extracted from the Summary of the Census, I881, Ages of the People, Table F, Vol. IV, p. 22, et seq.:

Number Per Cent Living at Each Age.

\begin{tabular}{|c|c|c|c|c|c|c|c|c|c|c|}
\hline & GE. & 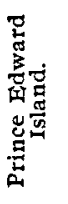 & 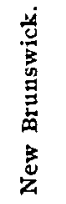 & 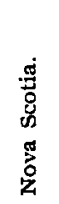 & 总 & $\begin{array}{l}\dot{y} \\
\text { 岁 } \\
\text { व }\end{array}$ & 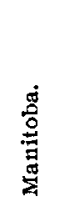 & 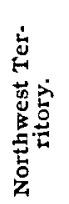 & 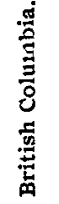 & 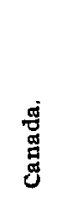 \\
\hline o & . & 2.73 & 2.75 & 2.52 & 2.62 & 3.29 & 2.89 & 0.46 & I. 75 & 2.80 \\
\hline I & . & 2.29 & $2.3^{8}$ & 2.24 & 2.27 & 2.35 & 2.63 & 0.50 & I. 54 & 2.28 \\
\hline 5 & . & $2.7 \mathrm{I}$ & 2.65 & 2.65 & 2.73 & 2.92 & 2.49 & 0.54 & 2.12 & 2.75 \\
\hline $2 I$ & . & I.99 & 1.92 & 1.89 & 2.09 & 1.92 & 2.36 & 0.37 & 1.21 & 1.98 \\
\hline
\end{tabular}

The causes of such a heavy infant mortality as appears from the above table cannot be far to seek, but perhaps an extract from a letter received from Dr. E. Persillier La [23I] 
Chapelle, President of the Conseil d'Hygiène of the Province of Quebec, in answer to inquiries, may suffice:

"I do not believe it would be correct to ascribe to any single cause the phenomenon you inquire about, and I am convinced it is the result of several factors. For one the first cause of the heavy infant mortality among the French Canadians is their very heavy natality, each family being composed of an average of twelve children, and instances of families of fifteen, eighteen and even twentyfour children being not uncommon.

"The superabundance of children renders, I think, parents less careful about them, and I have no doubt that for one instance, the want of care about the alimentary diet is an important cause of their premature death, and may explain the abnormal proportion of deaths from diarrhœa during the summer months; and this, not on account of poor or insufficient food, but on account of babies being allowed to drink and even eat anything they want and at any time, just the same as grown-up persons.

"In a word, I think that want of proper care in every way is the principal cause of this heavy infantile mortality, and I am sure it is not due to any constitutional or radical debility."

Whether or not we must regard this heavy infantile mortality among the French Canadians as arising from the operation of any one of Malthus' checks on the principle of population and whether, in the event, we should require to class lack of parental care and watchfulness as arising from vice or from misery, is really beside our purpose. What we have established is that the French Canadian race increases at no abnormal rate, for after the first year the proportion living at any given age varies little from the proportion among other Canadians.

These, then, are the conditions and the measure in which the French Canadian people meet them. No other race seems to offer the same facilities for calculating the standard 
rate of increase; and the resulting standard may be accepted with confidence. Malthus hastily assumed the standard of increase of 3.19 per annum, and a good deal of the discussion has arisen because his critics had no confidence that it was a true standard. It was hastily assumed and was based on conjectural estimates which might be trustworthy and might not; it was the casual increase of particular and restricted districts without allowance made for temporary and disturbing causes. That the rate he assumed was so near the true natural rate as it was, was probably due as much to "good luck as to good management," but at any rate it was near the true rate, and the "Principles of Population," with its discussion of the operation of the checks on the principle, remains of permanent value.

We have taken the Census of 1765 as our starting point. Emigration had practically ceased by this date; peace and freedom of development were secured to the race by treaty. From 1765 to $1890-9$ I we have 125 years of uninterrupted growth-a period long enough to afford a permanent standard of the productive capabilities of the race, and during the greater part of the period we have accurate statistics of population. A certain degree of uncertainty enters into the figures given from 1784 to 1844 . The Census of 1784 was taken before the influx of the Loyalists into the Eastern townships of what is now the Province of Quebec, but is said to include some fifteen thousand British settlers. From 1784 onward the total given without distinctions includes an increasing number of British settlers, and it is only possible by estimating the proportion of Irish among the Catholics of Quebec at a diminishing rate the further back we go from 1844 . From I 844 onward discrimination is made between English and French Canadians. The intermediate stages are not of much importance because the standard depends on the total increase from 1765 to $1890-91$. From 1851 the number of emigrants is included, which accounts for the sudden increase between 1844 and 1851 . The number of emigrants set down [233] 
in the table for the four decade years, I85I, I86I, I87 I, I $88 \mathrm{I}$, has been obtained by calculation. The United States Census Bulletins give only the total Canadian immigration into the United States for these periods; it is only for 189 I that we can definitely set down the number of French Canadians. However, it appears that in $189 \mathrm{I}$ the French Canadians were to the English Canadians in the proportion of 5 to II; and the totals given in Census Bulletin 357 are of the total Canadian population at the respective censuses of $1850,1860,1870$, 1880. If, then, we take for these the same or a less proportion of the total Canadian population in the United States, we shall reach substantial accuracy for each decennial period. For $185^{\circ}$ the proportion is $4: 1 \mathrm{I}$; for $1880,5: \mathrm{II}$; for 1860 and 1870 , midway between. It is necessary to reduce the proportion in this way because the French Canadian joined the Exodus, in large numbers, later than the English Canadians, as one would naturally expect. By the calculation for these years we get rid of the difficulty which it is said arises when we compare the Canadian Census of I88I made on the de jure plan with the census of I89I which was made on the de facto. Mr. Johnson, the statistician of the Canadian Board of Agriculture, estimates ('Toronto Empire Mail, February 18, 1895), that the change of system involved a difference of four per cent. If that were so, we should require to deduct some forty thousand from $\mathrm{I} 88 \mathrm{I}$ in order to obtain a true statement of the total French Canadian population for that year. However, absolute accuracy is not necessary at any intermediate stages, provided that at the starting point and at the end of the period there is no doubt. The census of ${ }_{17} 6_{5}$ is indubitably accurate, and the de facto system of the Canadian Census of I89 I enables us to count in the total return made by the United States Census Bulletins without any danger of counting any considerable section of the French Canadian twice over. 
Growth of the French Canadian Race.

Table of French Canadian Population, 1765-1891.

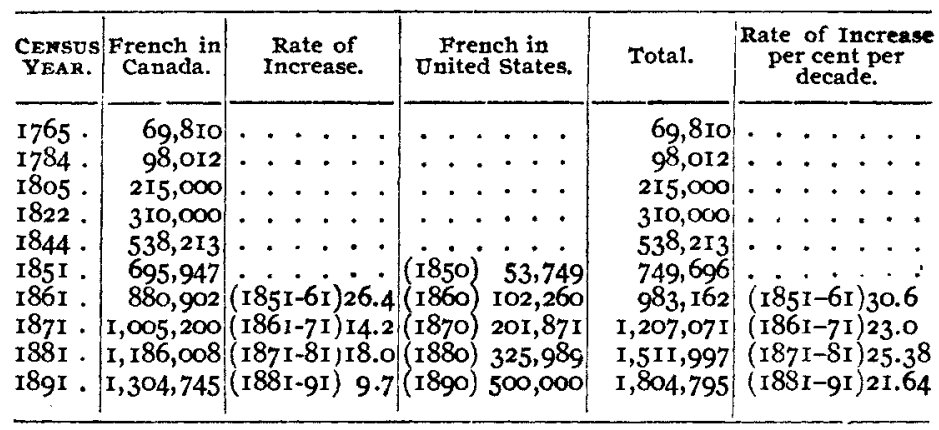

The resulting rate of increase per cent per decade from 1765 to $1890-91$ is 29.7 , which gives the result that the French Canadian population has doubled itself every twentyseven years. Malthus accepted as his standard a doubling every twenty-five, and the result of our investigation practically corroborates his standard, and justifies to some extent at least the disproportions of his treatise.

Universily of New Brunswick.

JoHN DAvidson. 